Ambiente \& Água - An Interdisciplinary Journal of Applied Science
ISSN 1980-993X - doi:10.4136/1980-993X
www.ambi-agua.net
E-mail: ambi-agua@agro.unitau.br

\title{
Ocorrência de chumbo e zinco nos solos e plantas às margens de uma rodovia de tráfego veicular intenso
}

\author{
doi: 10.4136/ambi-agua.1256 \\ Received: 16 Aug. 2013; Accepted: 18 Nov. 2013 \\ Luis Celso da Silva ${ }^{1 *}$; Julio Cesar Raposo de Almeida ${ }^{2}$; Ana Aparecida da Silva \\ Almeida ${ }^{2}$ \\ ${ }^{1}$ Universidade Federal Fluminense - UFF, Volta Redonda - RJ \\ ${ }^{2}$ Universidade de Taubaté - UNITAU, Taubaté - SP \\ *Autor correspondente: e-mail: luiscelso@id.uff.br, \\ jcraposo@uol.com.br, anasilva@unitau.br
}

\section{RESUMO}

A ocorrência de chumbo $(\mathrm{Pb})$ e zinco $(\mathrm{Zn})$ foram determinadas em amostras de solo e de gramíneas coletadas em três pontos de um trecho de $143 \mathrm{~km}$ da rodovia Presidente Dutra, entre os estados de São Paulo e Rio de Janeiro, nas distâncias perpendiculares de 0-10 m, 10$20 \mathrm{~m}, 20-35 \mathrm{~m}$ e $35-50 \mathrm{~m}$ da margem da rodovia. As concentrações de $\mathrm{Pb}$ e de $\mathrm{Zn}$ foram maiores nas amostras mais próximas da rodovia, diminuindo com o aumento da distância da rodovia, tanto nas amostras de solo, quanto nas amostras de planta. Os coeficientes de correlação entre concentração do metal no solo e concentração do metal na planta foram positivos, tanto para $\mathrm{Pb}$ quanto para $\mathrm{Zn}$. De modo geral, as concentrações de $\mathrm{Pb}$ encontradas nas amostras de solo foram inferiores ao valor de referência de qualidade estabelecido para os solos no estado de São Paulo. Já para o Zn, até 10 m de distância da margem da rodovia a concentração foi superior ao valor de referência.

Palavras-chave: poluição do solo, metais pesados, contaminação ambiental.

\section{Occurrence of lead and zinc in soils and plants at the margins of a highway with heavy traffic}

\begin{abstract}
The occurrences of lead $(\mathrm{Pb})$ and zinc $(\mathrm{Zn})$ were determined in soil and grasses collected at three points on stretch of $143 \mathrm{~km}$ of the Presidente Dutra highway between the states of São Paulo and Rio de Janeiro. The soil and plant samples were collected by sampling transections perpendicular to the highway at distances of $0,10,20,35$ and $50 \mathrm{~m}$ from the highway edge. Concentrations of $\mathrm{Pb}$ and $\mathrm{Zn}$ were higher in samples closest to the highway edge, decreasing with increasing distance from the road. There were positive correlation coefficients between the metal concentration in the soil and the metal concentration in the plant. Concentrations of $\mathrm{Pb}$ found in soil samples were below the reference value established for the soil quality in the state of São Paulo, while for $\mathrm{Zn}$, up to $10 \mathrm{~m}$ away from the highway edge, the concentration was higher than the reference value.
\end{abstract}

Keywords: soil pollution, heavy metals, environmental contamination. 


\section{INTRODUÇÃO}

O desenvolvimento tecnológico trouxe consigo grandes benefícios às sociedades, mas paralelamente também trouxe a poluição. O uso crescente de veículos automotores tem contribuído para o aumento desse problema. Segundo dados da Associação Nacional de Fabricantes de Veículos (ANFAVEA, 2012), a frota mundial estimada de veículos automotores em 2011 superava um bilhão, sendo a frota brasileira a oitava colocada, com mais de 34 milhões de unidades.

A despeito da evolução nos conceitos de produção dos veículos automotores, a frota brasileira ainda apresenta unidades cujos motores emitem consideráveis quantidades de poluentes, como o monóxido de carbono, hidrocarbonetos, óxidos de nitrogênio, óxidos de enxofre e materiais particulados, com a liberação de metais pesados originados de combustíveis, do vazamento de óleo dos motores (Li et al.. 2001), do desgaste de pneus (Davis et al., 2001) e materiais de freios (Grantz et al., 2003).

Com o incremento da produção de veículos flex-fuel, o Brasil destaca-se no uso de etanol anidro, biocombustível menos poluente que inicialmente foi empregado como um aditivo na gasolina, para aumentar sua octanagem, substituindo os compostos organometálicos contendo chumbo (Pb) (Leite e Cortez, 2007). Apesar de ser menos poluente do que os combustíveis derivados do petróleo, o etanol apresenta diversos contaminantes inorgânicos, como o $\mathrm{Pb}$ (Bergamini et al., 2006).

Outros contaminantes inorgânicos também estão presentes nos particulados provenientes da poluição veicular, como o zinco ( $\mathrm{Zn}$ ). O Zn é metal comum em óleos que minimizam o desgaste dos motores e de câmaras de combustão (Davis et al., 2001), em materiais de freios e em pneus ( $\mathrm{Li}$ et al., 2001), sendo esperada a sua presença em particulados associados ao tráfego de veículos.

Solos contaminados por metais normalmente estão associados a áreas industriais ou de elevada densidade populacional, o que eleva a preocupação sobre contaminação dos solos e plantas por $\mathrm{Pb}$ e $\mathrm{Zn}$, tendo em vista seus aspectos de frequência, toxicidade e potencial de exposição (ATSDAR, 2011). Dentre os efeitos tóxicos do Zn destacam-se a inibição da cadeia transportadora de elétrons na respiração e enzimas metabolismo oxidativo (Choudhury e Srivastava, 2001; Nweke et al., 2007; Nweke, 2009). Os efeitos tóxicos do Pb em eucariotos já são conhecidos há muito tempo, por afetarem praticamente todos os sistemas metabólicos (Xie et al., 1998).

Desde 2001 o estado de São Paulo dispõe de uma normativa com parâmetros e valores indicadores para a qualidade do solo (CETESB 2005). Recentemente, o Ministério do Meio Ambiente promulgou a Resolução 420/2009 (Brasil, 2009), que dispõe sobre critérios e valores orientadores de qualidade do solo e estabelece diretrizes para o gerenciamento ambiental de áreas contaminadas.

O chamado vale do Paraíba, uma região socioeconômica no sudeste do Brasil que abrange uma das maiores áreas industriais e urbanas do País, estende-se em grande parte da bacia hidrográfica do rio Paraíba do Sul. Região de elevado crescimento urbano e industrial, apresenta-se em progressiva degradação ambiental, o que pode ser observado a partir do seu principal acesso rodoviário, a rodovia Presidente Dutra (BR-116).

Concentrações elevadas de metais pesados em solos e na vegetação de áreas marginais de rodovias e estradas foram encontradas em várias regiões do mundo, como nos Estados Unidos (Lagerwerf e Specht, 1970), na Síria (Othman et al., 1997), na Jordânia (Jaradat \& Momani, 1999), no Brasil (Duarte e Pasqual, 2000) e na Austrália (Markus e Mc Bratney, 2001), tendo em vista a contínua perturbação antropogênica nessas áreas.

Assim, o objetivo deste estudo foi determinar a ocorrência de $\mathrm{Pb}$ e $\mathrm{Zn}$ no solo e na vegetação às margens da rodovia Presidente Dutra, considerando ser essa uma região de 
contínua alteração, devido à poluição advinda do tráfego veicular intenso e da industrialização.

\section{MATERIAL E MÉTODOS}

O presente estudo utilizou amostras de solo e de plantas coletadas às margens da rodovia Presidente Dutra (BR-116), no trecho entre os quilômetros 132-SP e 325-RJ, respectivamente entre os municípios de Caçapava-SP e Itatiaia-RJ, perfazendo $143 \mathrm{~km}$ de fluxo viário intenso. Foram estabelecidas três áreas de estudo às margens da rodovia: P1: km 132-SP; P2: km 48SP e P3: km 325-RJ. Em cada um desses pontos demarcaram-se quatro distâncias perpendiculares, de 0-10 m, 10-20 m, 20-35 m e 35-50 m da margem da rodovia, e a cada distância foram realizadas 10 amostragens simples de solo nas profundidades de $0-10 \mathrm{~cm}$ e 10-20 cm, totalizando 240 amostras.

No Laboratório de Análise de Solos e Plantas do Departamento de Ciências Agrárias da Universidade de Taubaté, as amostras de terra foram secas ao ar, destorroadas, homogeneizadas e passadas através de uma peneira de $1 \mathrm{~mm}$ de malha. Após digestão nitroperclórica das amostras, as concentrações totais de $\mathrm{Pb}$ e $\mathrm{Zn}$ foram determinadas por espectrofotometria de absorção atômica, Além disso, também foram realizadas as análises físicas e químicas das amostras de solo, para se determinar o pH, matéria orgânica, argila, silte e capacidade de troca catiônica (CTC), de acordo com o manual de métodos de análise de solo da EMBRAPA (1997).

Nos mesmos pontos de coleta das amostras de solo foram retiradas quatro amostras, compostas de quinze amostras individuais de gramíneas ocorrentes nas áreas: capim braquiária (Brachiaria sp) e capim gordura (Melinis minutiflora).

As amostras do material vegetal, folhas e hastes foram lavadas e, em seguida, secas em estufa com circulação de ar até peso constante, moídas e também submetidas à digestão nitroperclórica, segundo Tedesco et al. (1995). Os extratos foram analisados por espectrofotometria de absorção atômica, para a determinação de $\mathrm{Pb}$ e Zn.

Os resultados para as concentrações de $\mathrm{Pb}$ e $\mathrm{Zn}$ no solo, bem como as concentrações de $\mathrm{Pb}$ e $\mathrm{Zn}$ no material vegetal foram submetidos à análise de variância. Em caso de $\mathrm{F}$ significativo, realizou-se análise de regressão (Pimentel Gomes, 1984) para as áreas estudadas. Para os parâmetros químicos e físicos do solo e concentrações de $\mathrm{Pb}$ e $\mathrm{Zn}$, foi feito estudo de correlação simples.

\section{RESULTADOS E DISCUSSÃO}

Os resultados das análises de $\mathrm{pH}$, matéria orgânica (MO), argila, silte e capacidade de troca de catiônica (CTC) são apresentados na Tabela 1. Os valores de pH das áreas estudadas variaram de 3,8 a 4,5, sendo os menores valores encontrados nas maiores distâncias da rodovia. Segundo Martínez e Motto (2000), valores de pH menores que 5,2 elevam a disponibilidade de $\mathrm{Pb}$ e $\mathrm{Zn}$, portanto há menor retenção desses cátions na fase sólida dos solos e, consequentemente, maior absorção pelas plantas e maior risco de lixiviação (Corrêa et al., 2008).

O teor de MO variou de 18 a $46 \mathrm{~g} / \mathrm{dm}^{3}$, sendo maior em P1, em comparação a P2 e P3. A vegetação nas margens da rodovia Presidente Dutra é segmentada, sendo composta essencialmente por monocotiledôneas herbáceas de baixo porte, e o baixo aporte de resíduos biológicos reflete-se em teores baixos de MO. A presença de MO fornece condições para a formação de complexos insolúveis com metais pesados e outros elementos, tornando-os menos disponíveis às plantas e, assim, possibilitando o cultivo de plantas em áreas contaminadas (Ribeiro Filho et al., 2001). O estudo de correlação simples entre as variáveis 
$\mathrm{pH}, \mathrm{MO}$, argila, silte e CTC e as concentrações de $\mathrm{Pb}$ e de $\mathrm{Zn}$ foram significativas com $\mathrm{r}>$ 0,7. Autores como Valadares e Catani (1975), Souza et al. (1996) e Paye (2012) também encontraram correlações positivas entre o teor de argila e silte e os teores totais de $\mathrm{Pb}$ e $\mathrm{Zn}$. Todavia, Lavado et al. (1998) não encontraram correlação significativa para a MO e para o $\mathrm{pH}$. Verificou-se que as médias da saturação por bases (V\%) foram menores do que $50 \%$ para as áreas em estudo, isto é, 16,5\% para a área P1, 23\% para a área $\mathrm{P} 3$ e 17,3\% para a área P2, o que sugere que tais solos são distróficos.

Tabela 1. Valores de $\mathrm{pH}$, matéria orgânica (MO), argila, silte e capacidade de troca de catiônica (CTC) determinados nas três áreas às margens da rodovia Presidente Dutra (P1, P2 e P3), a distâncias perpendiculares de 0-10 $\mathrm{m}, 10-20 \mathrm{~m}, 20-35 \mathrm{~m}$ e 35-50 m.

\begin{tabular}{cccccc}
\hline $\begin{array}{c}\text { Área/Distância da } \\
\text { margem da } \\
\text { rodovia }\end{array}$ & $\mathrm{pH}$ & $\begin{array}{c}\mathrm{MO} \\
\mathrm{g} / \mathrm{dm}^{3}\end{array}$ & $\begin{array}{c}\text { Argila } \\
\mathrm{g} / \mathrm{kg}\end{array}$ & $\begin{array}{c}\text { Silte } \\
\mathrm{g} / \mathrm{kg}\end{array}$ & $\begin{array}{c}\mathrm{CTC} \\
\mathrm{cmolc} / \mathrm{dm}^{3}\end{array}$ \\
\hline P1 / 0-10 m & 4,5 & 30 & 512,5 & 31,8 & 5,1 \\
P1 / 10-20 m & 4,1 & 40 & 436,5 & 44,0 & 7,8 \\
P1 / 20-35 m & 4,0 & 44 & 465,0 & 52,0 & 8,6 \\
P1 / 35-50 m & 4,0 & 46 & 457,5 & 36,6 & 9,8 \\
P2 / 0-10 m & 4,5 & 43 & 266,0 & 108,4 & 9,2 \\
P2 / 10-20 m & 3,8 & 25 & 337,5 & 121,0 & 9,1 \\
P2 / 20-35 m & 3,9 & 25 & 263,0 & 110,8 & 9,0 \\
P2 / 35-50 m & 3,8 & 26 & 251,5 & 121,1 & 8,5 \\
P3 / 0-10 m & 4,1 & 23 & 259,0 & 117,0 & 7,1 \\
P3 / 10-20 m & 3,9 & 20 & 242,0 & 107,0 & 6,3 \\
P3 / 20-35 m & 3,8 & 18 & 246,0 & 73,0 & 6,4 \\
P3 / 35-50 m & 3,8 & 21 & 205,0 & 83,0 & 7,2 \\
\hline
\end{tabular}

As concentrações mais elevadas de $\mathrm{Pb}$ foram encontradas à distância de $0-10 \mathrm{~m}$ na camada superficial 0-10 cm (Tabela 2), o que sugere que há maior enriquecimento, nessa distância e profundidade, desse metal via fonte antropogênica, como tráfego veicular intenso e adições industriais, por ser essa uma região de grande crescimento urbano e industrial. Esses resultados são similares aos encontrados por Othman et al. (1997), os quais demonstram que o $\mathrm{Pb}$ originado da emissão por automotores incorporou-se nos solos vizinhos a rodovias, principalmente no intervalo de $10 \mathrm{~m}$ de distância da rodovia em até $20 \mathrm{~cm}$ de profundidade. As concentrações de $\mathrm{Pb}$ determinadas na camada de 0-10 cm, nas três áreas de estudo, variaram de 23,6 a $27,1 \mathrm{mg} \mathrm{Kg}^{-1}$, valores superiores aos relatados por Duarte e Pasqual (2000), para solos marginais a rodovias no oeste do estado de São Paulo, cujas concentrações de $\mathrm{Pb}$ variaram de 2,3 a $8,9 \mathrm{mg} \mathrm{Kg}^{-1}$. Para outros países, concentrações de $\mathrm{Pb}$ muito superiores foram determinadas como a variação de 78,4 a $832 \mathrm{mg} \mathrm{Kg}^{-1} \mathrm{em}$ solos marginais a rodovias, na Síria (Othman et al., 1997) e no mediterrâneo, com variação de 23 a $823 \mathrm{mg} \mathrm{Kg} \mathrm{Kg}^{-1}$ (Teutsch et al., 2001). Portanto, a maior concentração de $\mathrm{Pb}$ encontrada nas três áreas ao longo da rodovia Presidente Dutra foi cerca de 31 vezes menor do que os relatados nos referidos trabalhos.

Nas três áreas estudadas, verificou-se que as concentrações de $\mathrm{Pb}$ decrescem acentuadamente com a profundidade, o que se justifica pela baixa mobilidade desse metal nos solos (Markus e McBratney, 2001). Considerando 38 anos como o tempo de maior poluição 
ocasionada pelos veículos na rodovia Presidente Dutra, período este que vai desde a criação da rodovia, em 1951, até a substituição do chumbo pelo álcool, em 1989, pode-se estimar que a taxa de infiltração do $\mathrm{Pb}$ até a profundidade de $20 \mathrm{~cm}$ do solo sugere que ele tem penetrado no solo a uma velocidade de aproximadamente $0,5 \mathrm{~cm} \mathrm{ano}^{-1}$, similar ao valor reportado por Teutsch et al. (2001).

Quanto ao $\mathrm{Zn}$ no solo, verifica-se que há maior enriquecimento desse metal principalmente à distância de 0-10 m das margens da rodovia: $243,6 \mathrm{mg} \mathrm{Kg}^{-1}, 32,2 \mathrm{mg} \mathrm{Kg}^{-1} \mathrm{e}$ 40,2 $\mathrm{mg} \mathrm{Kg}^{-1}$ para as áreas P1, P2 e P3, respectivamente (Tabela 2). Tais valores sugerem um gradiente de deposição atmosférica de $\mathrm{Zn}$, o que, de acordo com Li et al. (2001), é ocasionado particularmente pelo desgaste de pneus devido a altas temperaturas nesses locais e por sua emissão por veículos automotores.

Tabela 2. Concentrações totais de $\mathrm{Pb}$ e $\mathrm{Zn}$ determinados nas três áreas às margens da rodovia Presidente Dutra (P1, P2 e P3) a distâncias perpendiculares de 0-10 m, 10-20 m, 20-35 $\mathrm{m}$ e $35-50 \mathrm{~m}$, e em duas profundidades.

\begin{tabular}{|c|c|c|c|}
\hline $\begin{array}{c}\text { Área/Distância da } \\
\text { margem da } \\
\text { rodovia }\end{array}$ & Profundidade & $\begin{array}{c}\mathrm{Pb} \\
\left(\mathrm{mg} \mathrm{Kg}^{-1}\right)\end{array}$ & $\underset{\left(\mathbf{m g ~ K g} \mathbf{g}^{-1}\right)}{\mathrm{Zn}}$ \\
\hline \multirow{2}{*}{$\mathrm{P} 1 / 0-10 \mathrm{~m}$} & $0-10 \mathrm{~cm}$ & 23,6 & 146,4 \\
\hline & $10-20 \mathrm{~cm}$ & 8,6 & 97,2 \\
\hline \multirow{2}{*}{$\mathrm{P} 1 / 10-20 \mathrm{~m}$} & $0-10 \mathrm{~cm}$ & 6,4 & 22,8 \\
\hline & $10-20 \mathrm{~cm}$ & 2,4 & 39,7 \\
\hline \multirow{3}{*}{$\mathrm{P} 1 / 20-35 \mathrm{~m}$} & $0-10 \mathrm{~cm}$ & 3,7 & 21,1 \\
\hline & $10-20 \mathrm{~cm}$ & 2,3 & 21,4 \\
\hline & $0-10 \mathrm{~cm}$ & 3,9 & 34,3 \\
\hline \multirow[t]{2}{*}{$\mathrm{P} 1 / 35-50 \mathrm{~m}$} & $10-20 \mathrm{~cm}$ & 1,7 & 18,0 \\
\hline & $0-10 \mathrm{~cm}$ & 24,4 & 72,6 \\
\hline \multirow[t]{2}{*}{$\mathrm{P} 2 / 0-10 \mathrm{~m}$} & $10-20 \mathrm{~cm}$ & 15,8 & 42,5 \\
\hline & $0-10 \mathrm{~cm}$ & 10,0 & 39,7 \\
\hline $\mathrm{P} 2 / 10-20 \mathrm{~m}$ & $10-20 \mathrm{~cm}$ & 8,9 & 36,0 \\
\hline \multirow{2}{*}{$\mathrm{P} 2 / 20-35 \mathrm{~m}$} & $0-10 \mathrm{~cm}$ & 8,7 & 32,1 \\
\hline & $10-20 \mathrm{~cm}$ & 7,5 & 36,5 \\
\hline \multirow[t]{3}{*}{$\mathrm{P} 2 / 35-50 \mathrm{~m}$} & $0-10 \mathrm{~cm}$ & 7,7 & 28,2 \\
\hline & $10-20 \mathrm{~cm}$ & 0,6 & 12,4 \\
\hline & $0-10 \mathrm{~cm}$ & 27,1 & 171,5 \\
\hline \multirow[t]{2}{*}{ P3 / 0-10 m } & $10-20 \mathrm{~cm}$ & 5,1 & 38,7 \\
\hline & $0-10 \mathrm{~cm}$ & 2,9 & 18,5 \\
\hline $\mathrm{P} 3 / 10-20 \mathrm{~m}$ & $10-20 \mathrm{~cm}$ & 1,2 & 30,2 \\
\hline \multirow{2}{*}{$\mathrm{P} 3$ / 20-35 m } & $0-10 \mathrm{~cm}$ & 4,5 & 18,0 \\
\hline & $10-20 \mathrm{~cm}$ & 1,0 & 24,5 \\
\hline \multirow{2}{*}{$\mathrm{P} 3 / 35-50 \mathrm{~m}$} & $0-10 \mathrm{~cm}$ & 3,1 & 16,8 \\
\hline & $10-20 \mathrm{~cm}$ & 7,3 & 24,7 \\
\hline
\end{tabular}

As correlações das concentrações de $\mathrm{Pb}$ e $\mathrm{Zn}$ nos solos das áreas em estudo apresentaram-se significativas, com $\mathrm{r}=0,9$, indicando que a origem desses metais está associada à mesma fonte de emissão. Nas áreas analisadas, a concentração de $\mathrm{Pb}$ nas camadas de 0-10 cm foi superior à encontrada na profundidade de $10-20 \mathrm{~cm}$. Esse resultado corrobora a afirmativa de que o $\mathrm{Pb}$ apresenta baixa mobilidade, acumulando-se na camada superficial na maioria dos solos (Abreu et al. (1998) e Teutsch et al. (1999, 2001), e decrescendo com o aumento da distância em relação às margens da rodovia, semelhantemente aos resultados 
obtidos por Othman et al. (1997), Pichtel et al. (1997), Markus e McBratney (2001) e Teutsch et al.(2001), sugerindo o enriquecimento do solo por fontes externas, como as emissões de particulados provenientes do tráfego intenso de veículos pela rodovia Presidente Dutra.

As maiores concentrações de $\mathrm{Pb}$ e $\mathrm{Zn}$ encontra-se na camada superficial do solo, sugerindo pequeno deslocamento desses metais em profundidade, o que deve ser considerado quando da amostragem de solo com a finalidade de estabelecer valores de contaminação ambiental. Entretanto, isso não é o suficiente para determinar todos os impactos ambientais causados por esses metais, pois parte deles pode estar em fases menos estáveis e lixiviar. Essa migração de poluentes pode alcançar os sistemas de drenagem das águas de chuvas e alcançar as águas superficiais e subterrâneas (Teutsch et al., 2001).

As variações na concentração de $\mathrm{Zn}$ com relação à profundidade não seguem a tendência observada na avaliação feita para o $\mathrm{Pb}$, pois o $\mathrm{Zn}$ apresenta maior mobilidade no solo ( $\mathrm{Li}$ et al., 2001) e solubilidade do que o Pb (Martinez e Motto, 2000). Assim, verificou-se que em alguns pontos a concentração de Zn na camada de 10-20 cm é maior do que na camada de 0$10 \mathrm{~cm}$.

Os resultados obtidos para as concentrações de $\mathrm{Pb}$ e $\mathrm{Zn}$ no solo, quando comparados com os valores-padrões de qualidade dos solos do estado de São Paulo (CETESB 195/05), 17 $\mathrm{mg} / \mathrm{kg}$ e de $60 \mathrm{mg} / \mathrm{kg}$, respectivamente, foram mais elevados na distância de $10 \mathrm{~m}$ da rodovia e na camada de $0-10 \mathrm{~cm}$.

As concentrações de $\mathrm{Pb}$ e $\mathrm{Zn}$ nos solos das três áreas analisadas, independentemente da distância, estabeleceram uma correlação positiva entre concentração de $\mathrm{Pb}$ e concentração de $\mathrm{Zn}$, sugerindo que as fontes de enriquecimento do solo são as mesmas (Figura 1).

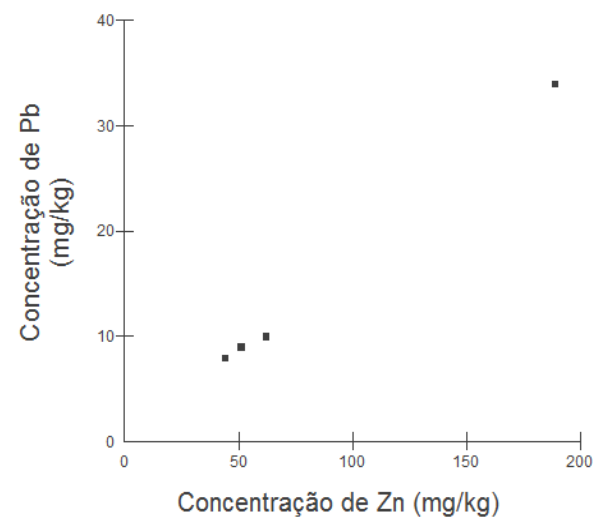

Figura 1. Correlação entre as concentrações de $\mathrm{Pb}$ e $\mathrm{Zn}$ no solo nas três áreas às margens da rodovia Presidente Dutra (P1, P2 e P3). r = $0,928 * *$

Observa-se, na Tabela 3, que a concentração de $\mathrm{Pb}$ e $\mathrm{Zn}$ no material vegetal variou, respectivamente, de 0,1 a 5,6 $\mathrm{mg} \mathrm{Kg}^{-1}$, e de 21 a 93,1 $\mathrm{mg} \mathrm{Kg}^{-1}$. As plantas coletadas na área P1 foram as que apresentaram os maiores valores de concentração de Pb, e nas áreas P1 e P2 as plantas coletadas até $35 \mathrm{~m}$ de distância da rodovia apresentaram concentração de $\mathrm{Pb}$ acima de $2 \mathrm{mg} \mathrm{Kg}^{-1}$, valor sugerido por Kabata-Pendias e Pendias (1984) e Palácios et al. (2002) como concentração de $\mathrm{Pb}$ encontrada em plantas provenientes de áreas não contaminadas. De acordo com Palácios et al. (2002), a quantidade de Pb que transloca para os brotos pode ser de até $30 \%$ da quantidade absorvida pelas raízes, o que indica que a absorção total de $\mathrm{Pb}$ pelas gramíneas foi ainda muito maior. 
Para a concentração de $\mathrm{Zn}$, as três áreas apresentaram valores inferiores a $150 \mathrm{mg} \mathrm{Kg}^{-1}$. Segundo Mulligan et al. (2001), são níveis encontrados em plantas provenientes de áreas não contaminadas.

As concentrações de $\mathrm{Pb}$ e de $\mathrm{Zn}$ nas plantas foram decrescentes, em relação à distância das margens da rodovia, corroborando trabalho de Othman et al. (1997), com relação ao metal $\mathrm{Pb}$. Essa evidência de maior absorção de $\mathrm{Pb}$ e $\mathrm{Zn}$ pelas plantas a pequenas distâncias provavelmente decorre do maior enriquecimento desses metais no solo, ocasionado pelas emissões desses metais pelos veículos automotores.

Tabela 3. Concentrações de $\mathrm{Pb}$ e $\mathrm{Zn}$ nas plantas (parte aérea) coletadas nas três áreas às margens da rodovia Presidente Dutra (P1, P2 e P3). ND= não detectado.

\begin{tabular}{ccc}
\hline $\begin{array}{c}\text { Área/Distância } \\
\text { da margem da } \\
\text { rodovia }\end{array}$ & $\begin{array}{c}\mathbf{P b} \\
\left(\mathbf{m g ~ K g}^{-\mathbf{1}}\right)\end{array}$ & $\begin{array}{c}\mathbf{Z n} \\
\left(\mathbf{m g ~ K g}^{-\mathbf{1}}\right)\end{array}$ \\
\hline $\mathrm{P} 1$ / 0-10 m & 5,6 & 34,1 \\
$\mathrm{P} 1$ / 10-20 m & 4,3 & 23,6 \\
P1 / 20-35 m & 2,7 & 23,6 \\
P1 / 35-50 m & 0,5 & 21,0 \\
P2 / 0-10 m & 3,2 & 61,9 \\
P2 / 10-20 m & 2,7 & 51,1 \\
P2 / 20-35 m & 2,4 & 28,1 \\
P2 / 35-50 m & 0,2 & 26,1 \\
P3 / 0-10 m & 1,1 & 93,1 \\
P3 / 10-20 m & 0,3 & 62,5 \\
P3 / 20-35 m & 0,1 & 58,3 \\
P3 / 35-50 m & N.D & 48,3 \\
\hline
\end{tabular}

Para ambos, $\mathrm{Pb}$ e $\mathrm{Zn}$, a concentração total na planta aumentou com a concentração total do solo, de modo que as correlações foram positivas e significativas (Figura 2 e Figura 3). Bharti e Singh (1993) e Paiva et al. (2003) relataram que o Pb acumula-se preferencialmente nas raízes, tendo baixa translocação para a parte aérea.



Figura 2. Correlação entre a concentração de $\mathrm{Pb}$ no solo e a concentração de $\mathrm{Pb}$ nas plantas, nas três áreas às margens da rodovia Presidente Dutra (P1, P2 e P3). r = $0,7667 * *$

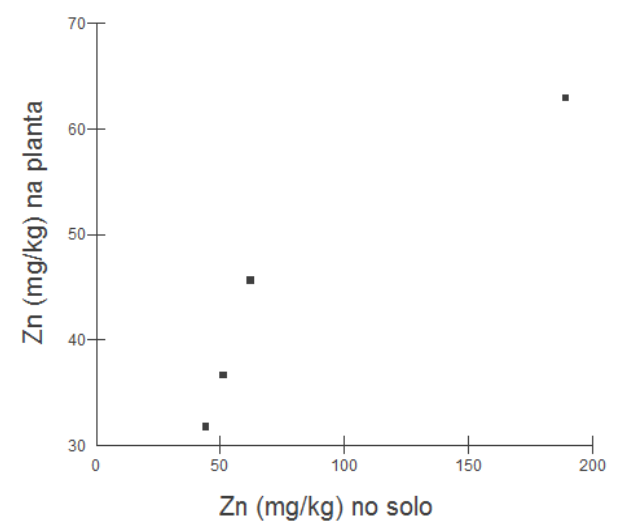

Figura 3. Correlação entre a concentração de $\mathrm{Zn}$ no solo e a concentração de $\mathrm{Zn}$ nas plantas, nas três áreas às margens da rodovia Presidente Dutra (P1, P2 e P3). r = $0,9477 * *$ 


\section{CONCLUSÕES}

1- O solo às margens da rodovia Presidente Dutra são relativamente contaminados com $\mathrm{Pb}$ e $\mathrm{Zn}$, mas essas concentrações são menores do que os valores de prevenção estabelecidos pela CETESB (2005) e CONAMA (Brasil, 2009).

2- Os metais pesados estão em maiores concentrações na camada superficial do solo, ou seja, até $10 \mathrm{~cm}$ de profundidade.

3- Há diminuição das concentrações de $\mathrm{Pb}$ e $\mathrm{Zn}$ nos solos e nas plantas com o aumento da distância da rodovia, o que indica a deposição de particulado no ambiente de estrada.

\section{REFERÊNCIAS}

ABREU, C. A.; ABREU, M. F.; ANDRADE, J. C. Distribuição de chumbo no perfil do solo avaliada pelas soluções DTPA e Mehlich 3. Bragantia, v. 57, n. 1, 1998. http://dx.doi.org/10.1590/S0006-87051998000100021

ASSOCIAÇÃO NACIONAL DOS FABRICANTES DE VEÍCULOS AUTOMOTORES ANFAVEA. Anuário estatístico da indústria automobilística 2012. Disponível em: <http://www.anfavea.com.br/anuario.html >. Acesso em: nov. 2012.

AGENCY FOR TOXIC SUBSTANCES AND DISEASE CONTROL - ATSDAR. CERCLA. The priority list of hazardous substances, 2011. Disponível em: <http://www.atsdr.cdc.gov/SPL/index.html >. Acesso em: nov. 2012.

BHARTI, N.; SINGH, R. P. Growth and nitrate reduction by Sesamum indicum CV PB-1 respond differentially to lead. Phytochemistry, v. 33, p. 531-534, 1993. http://dx.doi.org/10.1016/0031-9422(93)85443-U

BERGAMINI, M. F.; VITAL, S. I.; SANTOS, A. L.; STRADIOTTO, N. R. Determinação de chumbo em álcool combustível por voltametria de redissolução anódica utilizando um eletrodo de pasta de carbono modificado com resina de troca iônica Amberlite IR 120. Ecletica Química, São Paulo, v. 31, n. 2, 2006.

BRASIL. Conselho Nacional do Meio Ambiente - CONAMA. Resolução no 420/2009. Disponível em: < http://www.mma.gov.br/port/conama/legiabre.cfm?codlegi=620 >. Acesso em: nov. 2012.

COMPANHIA DE TECNOLOGIA DE SANEAMENTO AMBIENTAL - CETESB. Decisão de diretoria No195-2005. São Paulo, 2005. 4p.

CHOUDHURY, R.; SRIVASTAVA, S. Zinc resistance mechanisms in bacteria. Current Science, v. 8, n. 7, p. $768-775,2001$.

CORRÊA, J. C.; BÜLL, L. T.; PAGANINI, W. S.; GUERRINI. I. A. Disponibilidade de metais pesados em Latossolo com aplicação superficial de escória, lama cal, lodos de esgoto e calcário. Pesquisa Agropecuária Brasileira, v. 43, p. 411-419, 2008.

DAVIS, A. P.; SHOKOUHIAN, M.; NI, S. Loading estimates of lead, copper, cadmium and zinc in urban runoff from specific sources. Chemosphere, v. 44, p. 997-1009, 2001. http://dx.doi.org/10.1016/S0045-6535(00)00561-0

DUARTE, R. G. S.; PASQUAL, A. Avaliação do cádmio (Cd), chumbo (Pb), níquel (Ni) e zinco (Zn) em solos, plantas e cabelos humanos. Energia na Agricultura, Botucatu, v. 15 , n. 1, p. 46-58, 2000. 
EMPRESA BRASILEIRA DE PESQUISA AGROPECUÁRIA - EMBRAPA. Centro Nacional de Pesquisas de Solos. Manual de métodos de análise de solo. 2. ed. Rio de Janeiro, 1997. 212 p.

GRANTZ, D. A.; GARNER, J. H. B.; JOHNSON, D. W. Ecological effects of particulate matter. Environment International, v. 29, n. 2-3, p. 213-239, 2003. http://dx.doi.org/10.1016/S0160-4120(02)00181-2

JARADAT, Q.; MOMANI, K. Contamination of roadside soil, plants and air with heavy metals in Jordan, a comparative study. Turkish Journal of Chemistry, v. 23, p. 209$220,1999$.

KABATA-PENDIAS, A.; PENDIAS, H. Trace elements in soils and plants. Boca Raton: CRC Press, 315p. 1984.

LAGERWERFF, J. V.; SPECHT, A. W. Contamination of roadside soil and vegetation with cadmium, nickel, lead, and zinc. Environmental Science \& Technology, v. 4, n.7, p. 583-586, 1970. http://dx.doi.org/10.1021/es60042a001

LAVADO, R. S.; RODRIGUEZ, M. B.; SHEINER, I. D.; TABOADA, M. A.; RUBIO, G.; ALVAREZ. R. et al. Heavy metals in soils of Argentina: comparison between urban and agricultural soils. Communications in Soil Science and Plant Analysis, Athens, v. 29, n. 11/14, p. 1913-1917, 1998. http://dx.doi.org/10.1080/00103629809370081

LEITE, R. C.; CORTEZ, L. A. B. O etanol combustível no Brasil. In: MRE. (Org.). Biocombustíveis no Brasil - realidades e perspectivas. Brasília: MRE, 2007. p. 60-75. Disponível em: <http://ag20.cnptia.embrapa.br/Repositorio/etanol3_000g7gq2cz702wx5ok0wtedt3xdrmftk.pdf>. Acesso em: out. 2012.

LI, X.; POON, C. S.; LIU, P. S. Heavy metal contamination of urban soils and street dusts in Hong Kong. Applied Geochemistry, v. 16, n. 11/12, p. 1361-1368, 2001. http://dx.doi.org/10.1016/S0883-2927(01)00045-2

MARKUS, J.; McBRATNEY, A.B. A review of the contamination of soil with Lead II. Spatial distribution and risk assessment of soil Lead. Environment International, v. 27, p. 399-411, 2001. http://dx.doi.org/10.1016/S0160-4120(01)00049-6

MARTÍNEZ, C E.; MOTTO, H. L. Solubility of lead, zinc and cooper added to mineral soils. Environmental Pollution, v. 107, p. 153-158, 2000. http://dx.doi.org/10.1016/S02697491(99)00111-6

MULLIGAN, C. N.; YONG, R. N.; GIBBS, B .F. Remediation technologies for metalcontaminated soils and groundwater: an evaluation. Engineering Geology, v. 60, p. 193-207, 2001.

NWEKE, C. O. Kinetics of zinc toxicity to environmental bacterial isolates. Ambi-Água, v. 4, p. 23-34, 2009. http://dx.doi.org/10.4136/ambi-agua.100

NWEKE, C. O.; ALISI, C. S.; OKOLO; J. C.; NWANYANWU, C. E. Toxicity of Zinc to heterotrophic bacteria of tropical river sediments. Applied Ecology and Environmental Research, v. 5, n. 1, p. 123-132, 2007.

OTHMAN, I.; AL-OUDAT, M.; AL-MASRI, M. S. Lead levels in roadside soils and vegetation of Damascus city. The Science of the Total Environment, v. 207, p. 43-48, 1997. http://dx.doi.org/10.1016/S0048-9697(97)00243-X 
PALÁCIOS, H.; IRRIBARREN, I.; OLALLA, M. J.; CALLA, V. Lead poisoning of Horses in the vicinity of a battery recycling plant. The Science of the Total Environment, v. 290, p. 81-89, 2002. http://dx.doi.org/10.1016/S0048-9697(01)01066-X

PAIVA, H. P.; CARVALHO, J. G.; SIQUEIRA, J. O.; FERNANDES, A. R.; MIRANDA, J. R. P. Influência de doses crescentes de chumbo sobre o teor e o conteúdo de nutrientes e de $\mathrm{Pb}$ em mudas de ipê-roxo (Tabebuia impetiginosa (Mart.) Standl.). Revista Árvore, v. 27, p. 151-158, 2003. http://dx.doi.org/10.1590/S0100-67622003000200005

PAYE, H. S; MELlO, J. W. V; ABRAHÃO, W. A. P. A.; FERNANDES FILHO, E..I.; DIAS, L. C. P.; CASTRO, M. L. O. et al. Valores de referência de qualidade para metais pesados em solos no Estado do Espírito Santo. Revista Brasileira de Ciência do Solo, v. 34, n. 6, p. 2041-2051, 2012. http://dx.doi.org/10.1590/S0100-06832010000600028

PICHTEL, J.; SAWYERR, H. T.; CZARNOWSKA, K. Spatial and temporal distribution of metals in soils in Warsaw, Poland. Environment Pollution, v. 98, n. 2, p. 169-174, 1997. http://dx.doi.org/10.1016/S0269-7491(97)00131-0

PIMENTEL GOMES, F. A Estatística moderna na pesquisa agropecuária. Piracicaba: [s.n.], 1984. 160 p.

RIBEIRO FILHO, M. R.; SIQUEIRA, J. O.; CURI, N.; SIMÃO, J. B. P. Fracionamento e biodisponibilidade de metais pesados em solo contaminado, incubado com materiais orgânicos e inorgânicos. Revista Brasileira de Ciência do Solo, v. 25, p. 495-507, 2001.

SOUZA, M. L. P.; ANDREOLI, C. V.; AMARAL, M. B. et al. Levantamento preliminar dos teores de metais pesados em alguns solos do Paraná. Revista Sanare, Curitiba, v. 5, n. 5, p. 68-75, 1996.

TEDESCO, M. J; GIANELlO, C.; BISSANI, C. A.; BOHNEN, H.; VOLKWEISS, S. J. Análise de solo, plantas e outros materiais. 2. ed. Porto Alegre: UFRGS, 1995. 174 p. (Boletim Técnico, 5).

TEUTSCH, N.; EREL, Y.; HALICZ, L.; BANIN, A. Distribution of natural and anthropogenic lead in Mediterranean soils. Geochimica et Cosmochimica Acta, v. 65, n. 17, p. 2853-2864, 2001. http://dx.doi.org/10.1016/S0016-7037(01)00607-X

VALADARES, J. M. A. S.; CATANI, R. A. Zinco em solos do Estado de São Paulo: zinco total. Bragantia, Campinas, v. 34, p. 134 139, 1975.

XIE, Y.; CHIBA, M.; SHINOHARA, A.; WATANABE, H.; INABA, Y. Studies on leadbinding protein and interaction between lead and selenium in the human erythrocytes. Industrial Health, v. 36, p. 234-239, 1998. 